\title{
A High-Performance Supercapacitor Based on Nitrogen-Doped Porous Carbon Derived from Cycas Leaves
}

\author{
Chaochao Xu, Fen Xu*, Lixian Sun ", Lizhi Cao, Fang Yu, Huanzhi Zhang, Erhu Yan, \\ Hongliang Peng, Hailiang Chu, Yongjin Zou
}

Guangxi Key Laboratory of Information Materials, Guangxi Collaborative Innovation Center of Structure and Property for New Energy and Materials, School of Material Science and Engineering, Guilin University of Electronic Technology, Guilin, 541004, P. R. China

*E-mail:xufen@guet.edu.cn or 1732211579@qq.com, sunlx@guet.edu.cn

doi: $10.20964 / 2019.02 .26$

Received: 23 October 2018 / Accepted: 28 November 2018 / Published: 5 January 2019

In this work, we proposed a new way to synthesize nitrogen-doped porous carbon materials. Nitrogendoped porous carbon materials were prepared using cycas leaves as the carbon source and urea as the nitrogen source. Namely, the dried cycas leaves were first burned at $300{ }^{\circ} \mathrm{C}$ and then activated by $\mathrm{KOH}$ containing urea at $700^{\circ} \mathrm{C}$. The prepared samples display high specific surface areas; the highest specific surface area and largest total pore volumes are approximately $2628 \mathrm{~m}^{2} \mathrm{~g}^{-1}$ and $1.39 \mathrm{~cm}^{3} \mathrm{~g}^{-1}$, respectively. A supercapacitor made by nitrogen-doped porous carbon shows attractive capacitive performance. Taking CU2-700 as an example, its specific capacitance is $373 \mathrm{~F} / \mathrm{g}$ at $0.5 \mathrm{~A} / \mathrm{g}$, and $89 \%$ specific capacitance retention is reached after 10000 cycles in a three-electrode system. In addition, high specific capacitances of $260 \mathrm{~F} / \mathrm{g}$ at $0.5 \mathrm{~A} / \mathrm{g}$ and $203 \mathrm{~F} / \mathrm{g}$ at $10 \mathrm{~A} / \mathrm{g}$ are obtained, and CU2-700 has excellent cycling stability (85\% specific capacitance retention after 10000 cycles at $5 \mathrm{~A} / \mathrm{g}$ ) in a two-electrode system. Furthermore, the energy density of the supercapacitor is approximately $9.13 \mathrm{~W} \mathrm{~h} / \mathrm{kg}$ at $125 \mathrm{~W} / \mathrm{kg}$ power density in a two-electrode system. These results indicate that cycas leaves are a good biomass carbon material for preparing high-performance supercapacitors.

Keywords: cycas leaves; porous carbon; urea; $\mathrm{KOH}$ activation; supercapacitors

\section{$\underline{\text { FULL TEXT }}$}

(C) 2019 The Authors. Published by ESG (www.electrochemsci.org). This article is an open access article distributed under the terms and conditions of the Creative Commons Attribution license (http://creativecommons.org/licenses/by/4.0/). 